\title{
Modeling of Thermodynamic Properties and Phase Equilibria of the Si-P System
}

\author{
Song-Mao Liang and Rainer Schmid-Fetzer
}

(Submitted August 12, 2013; in revised form October 10, 2013; published online November 6, 2013)

\begin{abstract}
A Calphad assessment of the $\mathrm{Si}-\mathrm{P}$ system is performed based on critical review of all available original experimental thermodynamic and phase equilibrium data. It is demonstrated that a simple disordered substitutional solution model is sufficient for the liquid phase and that previous assumptions of short-range ordering in the Si-P liquid phase may not be justified. Alternative model descriptions for the Gibbs energy of the ( $\mathrm{Si}$ ) solid solution phase were developed to reveal the consequences in describing the largely scattering solid solubility data of $P$ in (Si). Two alternative sets of consistently calculated phase boundaries of the ( $\mathrm{Si}$ ) phase are shown. It is impossible to reconcile the only experimental ( $\mathrm{Si}$ ) solidus data with the solvus data from the same work.
\end{abstract}

Keywords Calphad assessment, phase equilibria, Si-P system, thermodynamic data

\section{Introduction}

Phosphorus is a key element in silicon device technology, such as semiconductor and solar cell materials. ${ }^{[1]}$ The phase equilibria of the Si-P binary system can provide some basic knowledge, and facilitate the comprehension of phenomena which are relevant for device technology. In addition, trace amounts of phosphorus can significantly affect the morphology of the eutectic microstructure in Al-Si alloys. $^{[2]}$ The Si-P binary system is, thus also an essential subsystem for developing thermodynamic databases for multi-component Al alloys. However, only few thermodynamic assessment works have been published for the Si-P system. Zaitsev et al. ${ }^{[3]}$ modeled the liquid phase of Si-P system assuming an associate solution model with two associates, $\mathrm{SiP}$ and $\mathrm{Si}_{2} \mathrm{P}$, based only on their own experimental activity data. ${ }^{[3]}$ Later, that author together with Arutyunyan et al. ${ }^{[4]}$ published another set of thermodynamic parameters of Si-P system again only based on the same experimental activity data $^{[3]}$ and using the same associate solution model. Jung and Zhang ${ }^{[5]}$ did the first full and serious thermodynamic assessment of the Si-P system in their work on the thermodynamic calculation of dephosphorization of silicon in molten slag. They modeled the liquid phase with the modified quasi-chemical model, which can only be readily used in the software FactSage, ${ }^{[6]}$ but only an earlier version of that model is implemented in Thermocalc $^{[7]}$ and it can not be used in Pandat ${ }^{[8]}$ either. In addition,

Song-Mao Liang, and Rainer Schmid-Fetzer, Institute of Metallurgy, Clausthal University of Technology, Robert-Koch-Str. 42, 38678 Clausthal-Zellerfeld, Germany. Contact e-mail: schmid-fetzer@ tu-clausthal.de. there may be some typos in their published parameters. Using FactSage we can reproduce the Si-P phase diagrams very close to the published ones only after correcting the liquid interaction parameter of $-5857.6^{[5]}$ to $-15857.6 \mathrm{~J} /$ mol, and the interaction parameter of the diamond phase from 2594.1-11.17 to 25941-11.17 $T \mathrm{~J} / \mathrm{mol}$. There is no experimental evidence at all of short-range ordering in Si-P liquid phase, thus, the modified quasi-chemical model or the associate solution model may not be justified compared to the simpler disordered substitutional solution model for the liquid phase.

The purpose of the present study is twofold: (i) to develop a consistent thermodynamic description for the Si-P system based on a meticulous analysis of all available original experimental data, demonstrating that a subregular solution model for the liquid phase is sufficient, and (ii) offering alternative descriptions for conflicting data on the solid solubility of $\mathrm{P}$ in ( $\mathrm{Si}$ ).

\section{Critical Review of Experimental Literature Data}

\subsection{Crystal Structure of Solid Phases}

Table $1^{[9-18]}$ presents the crystallographic data of all accepted solid phases in the Si-P system. Phosphorus exhibits various solid allotropic forms, but for this thermodynamic description, we only choose the red phosphorus and white phosphorus $(\alpha-\mathrm{P})$ for which thermodynamic parameters are provided by Dinsdale ${ }^{[19]}$. Detailed information on phosphorus allotropes is given in our previous paper on the Al-P system. ${ }^{[20]}$

Three silicon phosphides, $\mathrm{Si}_{2} \mathrm{P}, \mathrm{SiP}$ and $\mathrm{SiP}_{2}$, have been reported. The $\mathrm{Si}_{2} \mathrm{P}$ phase was only reported by Fritz and Berkenhoff, ${ }^{[21]}$ produced at $450{ }^{\circ} \mathrm{C}$ and decomposing into (Si) and SiP phase at $600{ }^{\circ} \mathrm{C}$. No any other publication mentioning - not to speak of verifying - the existence of this phase could be found, thus $\mathrm{Si}_{2} \mathrm{P}$ is not accepted in the present work. Beck and Stickler ${ }^{[12]}$ obtained a single crystal of SiP by 


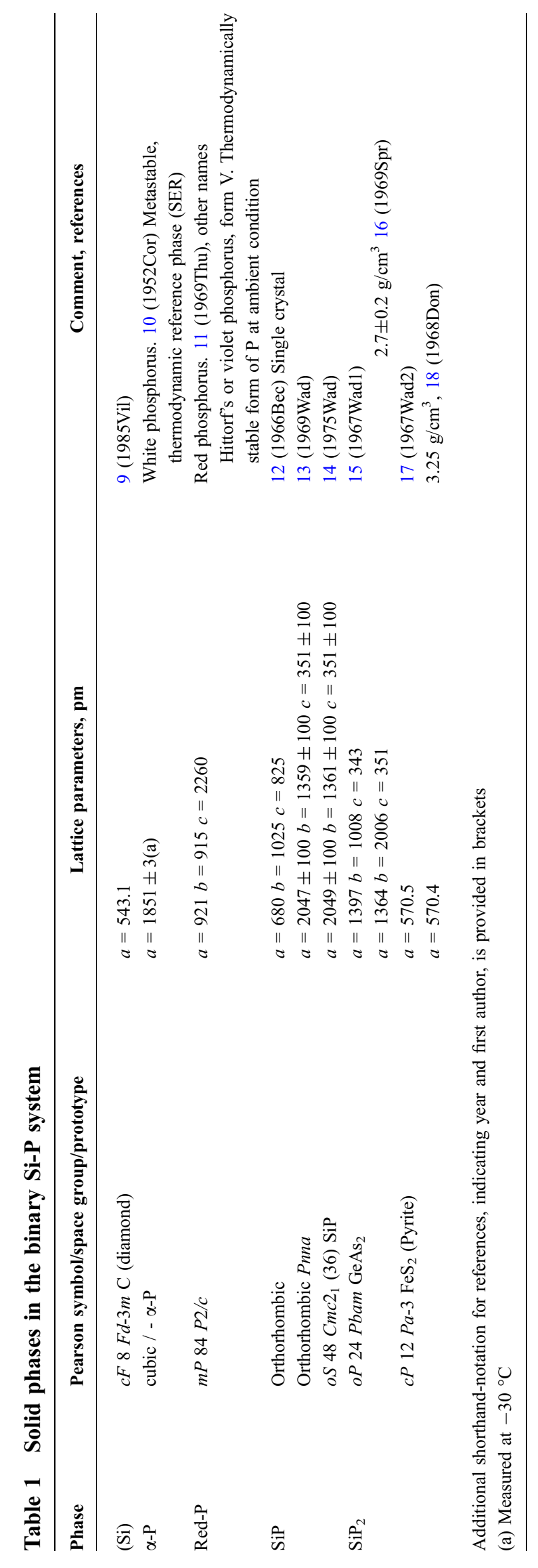

a vapor-growth method on Si matrix, and determined the structure of SiP as orthorhombic by x-ray diffraction (XRD) and transmission electron microscopy (TEM). Wadsten ${ }^{[13]}$ first determined the space group of orthorhombic SiP phase as Pnna, but in his later published paper ${ }^{[14]}$ the space group of $\mathrm{SiP}$ was changed into $\mathrm{Cmc2}_{1}$ (36), which is collected in the Pearson's database and cited in the review by Olesinski et al.. ${ }^{[22]}$ however, we failed to get the original paper. ${ }^{[14]}$ For the $\mathrm{SiP}_{2}$ phase two structures are reported, orthorhombic ${ }^{[15,16]}$ and pyrite-type. ${ }^{[17,18]}$ The pyrite-type $\mathrm{SiP}_{2}$ essentially formed at higher pressure (about 10 bar) using halogens as transporting agents. ${ }^{[17,18]}$ Differential thermal analysis in static air from room temperature to $1015{ }^{\circ} \mathrm{C}$ shows heating signals in the range $964-990{ }^{\circ} \mathrm{C}$ but no thermal activity was seen upon cooling. An x-ray powder diffraction pattern of the residue showed no starting phase, ${ }^{[18]}$ which demonstrates that pyritetype $\mathrm{SiP}_{2}$ is not a stable phase at ambient conditions. It decomposes irreversibly upon heating.

\subsection{Thermodynamic Data}

Ugai et al. ${ }^{[23]}$ measured the heat capacity of the SiP phase from 10 to $300 \mathrm{~K}$ using an adiabatic calorimeter. Based on these heat capacity data, the entropy of $\mathrm{SiP}$ at $298 \mathrm{~K}\left(S_{298}^{\mathrm{o}}\right)$ was determined to be $17.4 \mathrm{~J} / \mathrm{mol}$-atoms $/ \mathrm{K}$. No experimental information on the high temperature heat capacity of SiP is available. Korb and Hein ${ }^{[24]}$ measured the dissociation pressure of $\mathrm{SiP}$ in the temperature range between 900 and $1150{ }^{\circ} \mathrm{C}$, and they cited Biltz's ${ }^{[25]}$ work for comparison. But the original paper of Biltz ${ }^{[25]}$ is not available now, so we could only retrieve their data from Ref 24. Ugai et al. ${ }^{[26]}$ also measured the thermal dissociation of $\mathrm{SiP}$ from 1040 to $1210^{\circ} \mathrm{C}$ by a static manometric method. No direct experimental data on the standard enthalpy of formation $\left(\Delta_{\mathrm{f}} H^{\circ}\right)$ of SiP phase is available in the literature. In the review book, ${ }^{[27]}$ the $\Delta_{\mathrm{f}} H^{\circ}$ value of $\mathrm{SiP}$ was estimated to be $-30.95 \mathrm{~kJ} / \mathrm{mol}$-atoms, which was cited by the following two review books. ${ }^{[28,29]}$

Compared to the SiP compound, even less experimental work is published on the thermodynamic properties of $\mathrm{SiP}_{2}$. Only Philipp and Schmidt ${ }^{[30]}$ mentioned that the heat capacity was determined by DSC measurements as $C_{\mathrm{p}}\left(\mathrm{SiP}_{2}\right)=\left\{67.0(2)+17.1(4) \times 10^{-3} T\right\} \quad \mathrm{J} / \mathrm{K} / \mathrm{mol}$. However, they did not give any experimental detail.

Miki et al. ${ }^{[31]}$ measured the vapor pressure of phosphorous over Si-rich liquid from 1450 to $1575{ }^{\circ} \mathrm{C}$ using a chemical equilibration technique. Zaitsev et al. $^{[3]}$ used Knudsen effusion mass spectrometry and a static method to measure the vapor composition and thermodynamic properties of Si-P melt with phosphorous content from 0.09 to 26.5 at. $\%$ P.

A summary of the experimental thermodynamic and phase equilibrium investigations is given in Table 2.

\subsection{Phase Equilibrium Data}

Giessen and Vogel ${ }^{[32]}$ constructed the Si-P phase diagram from 0 to $30 \mathrm{wt} . \% \mathrm{P}$ based on their thermal analysis and metallographic results. Safarian and Tangstad ${ }^{[33]}$ determined the liquidus in the Si-rich region (0-6 wt.\% P) and eutectic temperature by thermogravimetric and differential thermal 


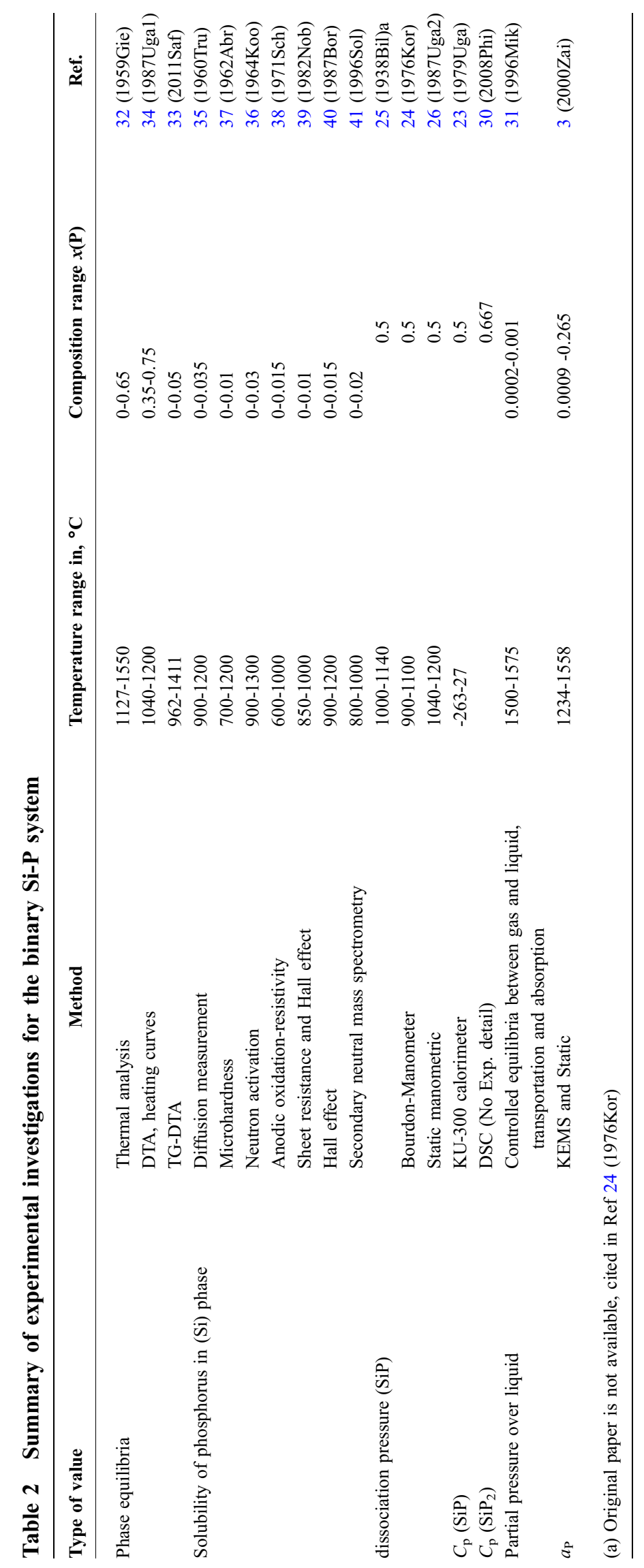


analysis (TG-DTA) experiments and the solidus temperature by TG results. Ugai et al. ${ }^{[34]}$ carried out the DTA experiments with controlled vapor pressure of the volatile component, and they produced the $\mathrm{Si}-\mathrm{P}$ phase diagram within the composition range 40-70 at.\% $\mathrm{P}$ under relatively high pressure, showing the congruent melting points of SiP and $\mathrm{SiP}_{2}$ phase. The $\mathrm{Si}-\mathrm{SiP}$ eutectic temperature determined by these three independent works is generally agreed upon.

Extensive investigation has been carried out on $[\mathrm{P}]_{(\mathrm{Si})}$, the solubility of $\mathrm{P}$ in the solid $(\mathrm{Si})$ phase. ${ }^{[35-41]}$ Trumbore ${ }^{[35]}$ referred to unpublished results of MacKintosh obtained by sheet resistance and junction depth measurements. Kooi ${ }^{[36]}$ using neutron activation analysis investigated the diffusion behavior of phosphorus in silicon, and obtained $[\mathrm{P}]_{(\mathrm{Si})}$ in the temperature range between 920 and $1310{ }^{\circ} \mathrm{C}$. Abrikosov et al. ${ }^{[37]}$ determined $[\mathrm{P}]_{(\mathrm{Si})}$ by microhardness measurement on bulk doped specimens. Schwettmann and Kendall ${ }^{[38]}$ measured the solubility data by sheet resistant method. Nobili et al. ${ }^{[39]}$ obtained $[\mathrm{P}]_{(\mathrm{Si})}$ of laser annealed specimens, doped by ion implantation, by Hall effect and resistivity measurement. Borisenko and Yudin ${ }^{[40]}$ determined $[\mathrm{P}]_{(\mathrm{Si})}$ from 900 to $1200{ }^{\circ} \mathrm{C}$ also by Hall effect measurement. Solmi et al. ${ }^{[41]}$ reported the solubility data from 800 to $1000{ }^{\circ} \mathrm{C}$ determined by secondary neutral mass spectrometry (SNMS) measurement.

The values reported by Trumbore ${ }^{[35]}$ and Kooi ${ }^{[36]}$ are in mutual satisfactory agreement, but they are about a factor of two higher than other, essentially later published values. $^{[37-40]}$ Nobili et al. ${ }^{[39]}$ pointed out that Trumbore's data $^{[35]}$ may not be reliable, because the approximation and error function involved in the calculation of the surface concentration is surely not justified, which was also pointed out by Mackintosh ${ }^{[42]}$ himself in a later work considering the actual shape of the profile. Nobili et al. ${ }^{[39]}$ also claimed that Kooi's data were questionable because their work was related to a $\mathrm{Si}-\mathrm{P}-\mathrm{O}$ ternary system rather than $\mathrm{Si}-\mathrm{SiP}$ binary equilibrium. Although those data ${ }^{[35,36]}$ are criticized by Nobili et al., ${ }^{[39]}$ they were accepted in a review by Olesinski et al. ${ }^{[22]}$ and later by Jung and Zhang ${ }^{[5]}$ for evaluation and optimization. We classify these data into two groups, group I is with lower solid solubility near the eutectic temperature, ${ }^{[38-40]}$ and group II presents higher solid solubility near the eutectic temperature. ${ }^{[35,36]}$

\section{Thermodynamic Modeling}

\subsection{Pure Elements}

The Gibbs energy function, $G_{i}^{0, \varphi}(T)=G_{i}^{\varphi}(T)-H_{i}^{S E R}$, of the pure element $(i)(i=\mathrm{Si}$ and $\mathrm{P})$, in any phase $\phi$ is described by an equation of the following form:

$$
\begin{aligned}
G_{i}^{0, \varphi}(T)= & a+b \cdot T+c \cdot T \cdot \ln T+d \cdot T^{2}+e \cdot T^{3} \\
& +f \cdot T^{-1}+g \cdot T^{7}+h \cdot T^{-9}
\end{aligned}
$$

where $H_{i}^{S E R}$ is the molar enthalpy of the element $(i)$ at $298.15 \mathrm{~K}$ and $1 \mathrm{bar}$ in its standard element reference (SER) state, which is diamond for $\mathrm{Si}$ and white phosphorus, $\alpha-\mathrm{P}$, for P. $T$ is the absolute temperature. By definition, the white

Table 3 Phase names, models (sublattice formula) and parameters of the Gibbs energy equations developed in present work

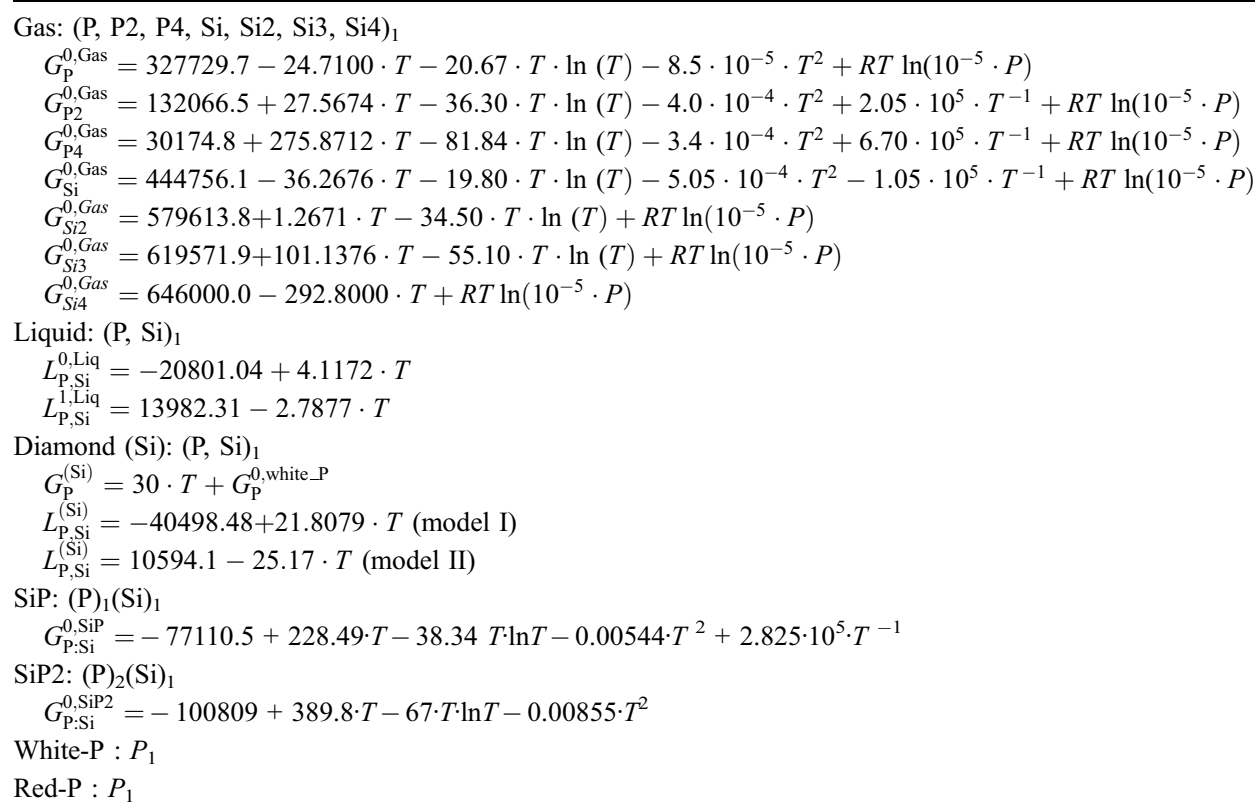

Gibbs energy is given in J/mol-formula, temperature $(T)$ in Kelvin and pressure $(P)$ in Pascal. The Gibbs energies for the pure elements are found in the SGTE compilation, ${ }^{[19]}$ and the Gibbs energies for gas species are recalculated from Ref 29 
form of $\mathrm{P}$ is chosen as the reference phase ${ }^{[19]}$ as opposed to the more stable red form. The Gibbs energy functions for $\mathrm{Si}$ and $\mathrm{P}$ are taken from the Scientific Group Thermodata Europe (SGTE) compilation by Dinsdale ${ }^{[19]}$. The solid phosphorous phases, $\alpha-P$ and red-P, are described as stoichiometric phases.

\subsection{Solution Phases}

The Gibbs energies for liquid and diamond-(Si) solution phases are described by the substitutional solution model as follows,

$$
\begin{aligned}
G^{\varphi}= & x_{\mathrm{P}} \cdot G_{\mathrm{P}}^{0, \varphi}+x_{\mathrm{Si}} \cdot G_{\mathrm{Si}}^{0, \varphi}+\mathrm{R} \cdot T \cdot\left(x_{\mathrm{P}} \cdot \ln x_{\mathrm{P}}+x_{\mathrm{Si}} \cdot \ln x_{\mathrm{Si}}\right) \\
& +x_{\mathrm{P}} x_{\mathrm{Si}}\left(L_{\mathrm{P}, \mathrm{Si}}^{0, \varphi}+L_{\mathrm{P}, \mathrm{Si}}^{1, \varphi}\left(x_{\mathrm{P}}-x_{\mathrm{Si}}\right)\right)
\end{aligned}
$$

where $x_{\mathrm{Si}}, x_{\mathrm{P}}$ represents the mole fraction of element $\mathrm{Si}$ and P. $\mathrm{R}$ is the gas constant $(\mathrm{R}=8.3145 \mathrm{~J} / \mathrm{mol} \mathrm{K})$ and $L_{P, S i}^{0, \varphi}$ and $L_{P, S i}^{1, \varphi}$ are the subregular solution parameter representing the interaction between components $\mathrm{Si}$ and $\mathrm{P}$. For diamond-( $\mathrm{Si})$ a regular solution with $L_{P, S i}^{1, \varphi}=0$ is used.

\subsection{Stoichiometric Compounds}

The $\mathrm{SiP}$ and $\mathrm{SiP}_{2}$ phases are treated as stoichiometric phases in the present modeling. The Gibbs energy of each stoichiometric phase is described with absolute reference state since this allows also a quantitative description of the heat capacity of each compound. For the example of SiP we have

$G^{\mathrm{SiP}}(T)=\mathrm{A}^{*}+\mathrm{B} \cdot T+\mathrm{C} \cdot T \cdot \ln T+\mathrm{D} \cdot T^{2}+\mathrm{E} / T$,

where

$\mathrm{A}^{*}=\mathrm{A}+G_{\mathrm{Si}}^{0, \text { diamond }}(298.15 \mathrm{~K})+G_{\mathrm{P}}^{0, \alpha-P}(298.15 \mathrm{~K})$

The Gibbs energies of pure elements at $298.15 \mathrm{~K}$ in Eq 4 correspond to the SER reference state from Eq 1. Coefficients $A^{*}$ and $B$ from $\mathrm{Eq} 3$ were optimized for all stoichiometric phases considering the entity of experimental data. Coefficients C, D and E are determined from the temperature dependence of the heat capacity, $C_{\mathrm{p}}$, and these values were kept constant during the optimizing procedure.

\subsection{Gas Phase}

The gas phase is described as an ideal gas mixture of gaseous species $\mathrm{Si}, \mathrm{Si}_{2}, \mathrm{Si}_{3}, \mathrm{Si}_{4}, \mathrm{P}, \mathrm{P}_{2}$ and $\mathrm{P}_{4}$. The Gibbs energy functions of the individual gas species are recalculated from the corresponding data for $\Delta_{\mathrm{f}} H^{\circ}, S_{298}^{\mathrm{o}}$, and $C_{\mathrm{p}}$ given by Binnewies and Milke ${ }^{[29]}$. The result is given in Table 3.

\subsection{Parameter Optimization}

The optimization started from the intermetallic compounds $\mathrm{SiP}$ and $\mathrm{SiP}_{2}$. First, the $\mathrm{C}, \mathrm{D}$ and $\mathrm{E}$ parameters of $\mathrm{SiP}$ and $\mathrm{SiP}_{2}$ phase were fixed based on the data suggested by Jung and Zhang, ${ }^{[5]}$ more reliable experimental heat capacity data on the two compounds are not available. Subsequently the $\mathrm{A}^{*}$ and $\mathrm{B}$ parameters of $\mathrm{SiP}$ and $\mathrm{SiP}_{2}$ were optimized according to the vapor pressure data and other phase equilibria data. During optimizing the interaction parameters of liquid phase, we put more weight on the partial pressure data obtained by Miki et al., ${ }^{[31]}$ and much less weight on the activity data of Zaitsev et al. ${ }^{[3]}$. Jung and Zhang ${ }^{[5]}$ did the same treatment for their optimization, and more detailed explanations will be given later. The available solubility data of phosphorus in silicon scatter significantly. We developed two sets of parameters for the diamond $(\mathrm{Si})$ phase based on the two groups of contradicting experimental solubility data identified in "Phase equilibrium data" section. Model I was optimized based on group I solid solubility data, with the small values of $[\mathrm{P}]_{(\mathrm{Si})}$ at the eutectic temperature. Model II was based on group II solid solubility data with larger values of $[\mathrm{P}]_{(\mathrm{Si})}$ at eutectic temperature and the solidus experimental data determined above $1350{ }^{\circ} \mathrm{C}$ by Safarian et al. ${ }^{[33]}$.

Thermodynamic calculations and the parameter optimization are performed using the Pandat software package (www.computherm.com) with PanOptimizer. ${ }^{[8]}$ Some comparative calculations were also done using the software packages FactSage ${ }^{[6]}$ and Thermo-calc. ${ }^{[7]}$ All thermodynamic Gibbs energy parameters determined in the present work are given in Table 3 . Note that only the interaction parameter of the ( $\mathrm{Si}$ ) phase is different for models I and II, all other parameters are the same for these two models.

\section{Results and Discussion}

\subsection{Phase Diagram}

Figure 1 shows the calculated Si-P phase diagram along with the experimental data. ${ }^{[32,33]}$ The calculated liquidus line and Si-SiP eutectic temperature at $1131{ }^{\circ} \mathrm{C}$ (model I) are in good agreement with the experimental data. ${ }^{[32,33]}$ Giessen and Vogel ${ }^{[32]}$ also tried to determine the vaporization temperature of liquid Si-P solution and corresponding gas composition using a rough estimation technique. We agree with the explanation by Jung and Zhang ${ }^{[5]}$ that their method is very inaccurate, and these data are not reliable. On the other hand, we also found that the evaporation line, $\mathrm{L} / \mathrm{L}+\mathrm{G}$ ( $\mathrm{L}$ denotes the liquid phase, $\mathrm{G}$ the gas phase), experimentally determined by Giessen and Vogel ${ }^{[32]}$ agrees better with the calculated line at a total pressure of $0.5 \mathrm{bar}$ compared to 1 bar, Fig. 1. A similar result was obtained by Jung and Zhang ${ }^{[5]}$.

The data for the condensation phase boundary, $L+G / G$, at 1 bar obtained experimentally by an observed mass chang ${ }^{[32]}$ are in the mid-composition range whereas the calculation shows virtually pure $\mathrm{P}$ in the gas phase. It is impossible to reconcile this discrepancy using any sensible thermodynamic calculation. The only way to come near to these data points is by speculating about an existence of extremely (!) stable Si-P molecules with a composition near 


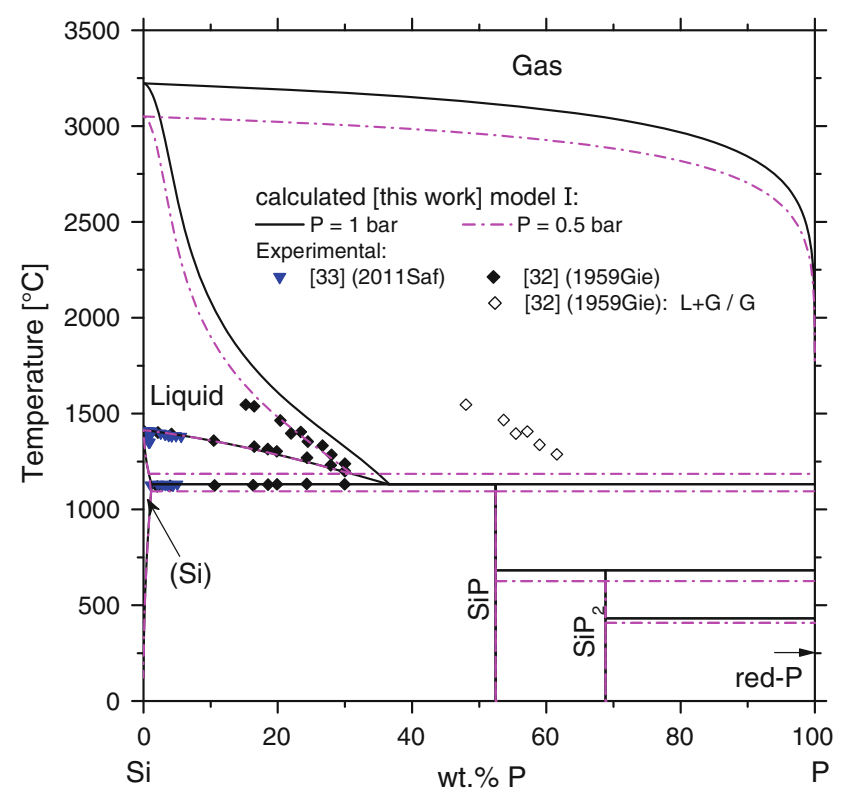

Fig. 1 Calculated Si-P phase diagram at 1 and 0.5 bar total pressure compared with experimental data. The $\mathrm{L} / \mathrm{L}+\mathrm{G}$ equilibrium experimental data obtained by Giessen and Vogel ${ }^{[32]}$ fit the calculated phase diagram at 0.5 bar. Additional shorthand-notation for references, indicating year and first author, is provided in brackets

$50 \% \mathrm{P}$ in the gas phase that might produce such a skewed condensation line. However, there is no evidence at all of such dominating molecules and therefore the reported data on the $\mathrm{L}+\mathrm{G} / \mathrm{G}$ boundary ${ }^{[32]}$ in Fig. 1 cannot be accepted.

In contrast to these findings the "calculated" phase diagrams presented by Zaitsev et al. ${ }^{[3]}$ and later by Arutyunyan et al. ${ }^{[4]}$ show a dashed $\mathrm{L}+\mathrm{G} / \mathrm{G}$ boundary right through the data points of. ${ }^{[32]}$ While Zaitsev et al. ${ }^{[3]}$ did not even state which model they used for the gas phase the later work by Arutyunyan et al. ${ }^{[4]}$ reveals that an ideal gas consisting of molecules $\mathrm{P}, \mathrm{P}_{2}$, and $\mathrm{P}_{4}$ was assumed. That, of course, results in a calculated gas phase composition of exactly $100 \% \mathrm{P}$ in stark contrast to the hand-plotted L + G/ $\mathrm{G}$ boundary at about 50 at.\% P. This discrepancy is not even pointed out or reflected in the discussion parts of. ${ }^{[3,4]}$ It is emphasized in the present work that only the $\mathrm{L}+\mathrm{G} / \mathrm{G}$ boundary shown in Fig. 1, at almost pure P below about $2000{ }^{\circ} \mathrm{C}$, is consistent with the current knowledge of Gibbs energy data of gas phase species compiled in Table 3.

The calculated Si-P phase diagram at higher pressure is shown in Fig. 2 compared with the experimental work. ${ }^{[32-34]}$ The congruent melting of the $\mathrm{SiP}$ and $\mathrm{SiP}_{2}$ phases occurs only at high pressure as detailed in Table 4. The calculated dashed $\mathrm{L} / \mathrm{L}+\mathrm{G}$ boundary corresponds to 200 bar and is shown as example only, the condensed phase equilibria are considered to be independent of pressure in this study. Red phosphorus starts melting when the pressure is higher than $32.7 \mathrm{bar}$, the calculated triple point at $579{ }^{\circ} \mathrm{C}$.

Safarian and Tangstad ${ }^{[33]}$ stated that they observed a turning point in the TG curves of Si-rich samples at $1139 \pm 2{ }^{\circ} \mathrm{C}$, which also appeared as endothermic reaction

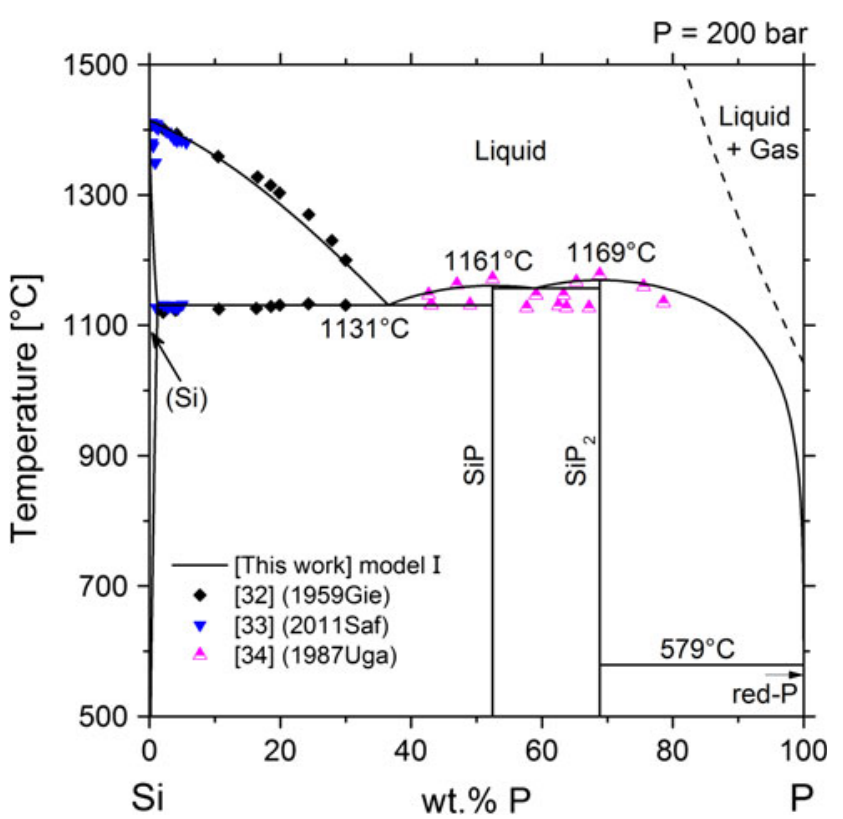

Fig. 2 Calculated phase diagram of the Si-P system at 200 bar compared with experimental data ${ }^{[32-34]}$

in the heating DTA curves, and they associated this with the melting point of the SiP phase. That value was accepted by Jung and Zhang ${ }^{[5]}$ for their optimization. However, we consider the statement by Safarian and Tangstad ${ }^{[33]}$ questionable for two reasons. Firstly, their experimental work was carried out only in the composition range of 0-4.3 wt.\% $\mathrm{P}$ under Ar gas with flow rate of $20 \mathrm{~mL} / \mathrm{min}$. At such low Pcontent the fraction of the SiP phase in the sample must be very small. Especially, we see in sample series $2-\mathrm{E}^{[33]}$ that the initial composition was only $0.77 \mathrm{wt} . \% \mathrm{P}$ and the final composition $0.34 \mathrm{wt} . \% \mathrm{P}$, which should be clearly in the (Si) single-phase region. However, they ${ }^{[33]}$ also claimed this thermal signal at $1141 \pm 2{ }^{\circ} \mathrm{C}$ to be the melting point of $\mathrm{SiP}$, which is unrealistic. Secondly, they explained that the melting of SiP phase should be prior to the eutectic reaction because a reaction taking place between two solid phases would be slower than one solid melting phase, and assumed that the melting point of SiP phase is only slightly above the eutectic temperature. Then, they concluded "... an average melting point for $\mathrm{SiP}$ at $1139 \pm 2{ }^{\circ} \mathrm{C}$. This melting point is close to the reported melting point $1140{ }^{\circ} \mathrm{C} \cdot .^{[27,43], " ~ B u t ~}$ when tracing back to the cited book $^{[27]}$ we found that the meaning of the reported " $1140{ }^{\circ} \mathrm{C}$ " was the thermal decomposition (!) temperature of SiP phase (not even the pressure is provided) giving a Ref 44. In the original paper, ${ }^{[4]}$ the main focus was on germanium phosphide, $\mathrm{GeP}$, while the thermal decomposition temperature of $\mathrm{SiP}$ phase was only mentioned at one atmosphere to be $1140{ }^{\circ} \mathrm{C}$ and another Ref 25 was given, which is also cited by Korb et al. $^{\left[{ }^{[2]}\right]}$ but the original source is not available. In the book, ${ }^{[43]}$ which is mainly a compacted version from, ${ }^{[22]}$ no information at all is provided on the "melting point" of SiP.

In addition to these less reliable experimental data by Safarian and Tangstad, ${ }^{[33]}$ we have found only one other 
Table 4 Invariant reactions in $\mathrm{Si}-\mathrm{P}$ system

\begin{tabular}{|c|c|c|c|c|}
\hline Reaction & $\mathrm{T},{ }^{\circ} \mathrm{C}$ & $\mathrm{P}$ in $(\mathrm{Si}), \mathrm{wt} \%$, at. $\%$ & $P$ in liquid, wt. $\%$, at. $\%$ & Reference/comments \\
\hline \multirow[t]{6}{*}{ Eutectic $\mathrm{L}=(\mathrm{Si})+\mathrm{SiP}$} & $1131 \pm 2$ & & $35 \pm 3$ & 32 (1959Gie) experimental \\
\hline & 1131 & & & 34 (1987Uga) experimental \\
\hline & $1129 \pm 2$ & $1.04(0.94)(a)$ & & 33 (2011Saf) experimental \\
\hline & 1127 & $4.17(3.80)$ & $42.9(40.5)$ & 5 (2012Jun) calculated \\
\hline & 1131 & $1.22(1.10)$ & $36.5(34.3)$ & [This work] model I(b) \\
\hline & 1134 & $3.96(3.60)$ & $37.2(35.0)$ & [This work] model II \\
\hline \multirow[t]{4}{*}{ Congruent melting $\mathrm{L}=\mathrm{SiP}$} & 1170 & & & 34 (1987Uga) experimental \\
\hline & $1139 \pm 2$ & & & 33 (2011Saf) experimental \\
\hline & 1137 & & & 5 (2012Jun) calculated \\
\hline & 1161 & & & [This work] models I \& II, $p=13$ bar \\
\hline \multirow{3}{*}{ Congruent melting $\mathrm{L}=\mathrm{SiP}_{2}$} & 1178 & & & 34 (1987Uga) experimental \\
\hline & 1156 & & & 5 (2012Jun) calculated \\
\hline & 1169 & & & [This work] models I \& II, $p=60$ bar \\
\hline \multirow[t]{3}{*}{ Eutectic $\mathrm{L}=\mathrm{SiP}+\mathrm{SiP}_{2}$} & 1125 & & & 34 (1987Uga) experimental \\
\hline & 1134 & & & 5 (2012Jun) calculated \\
\hline & 1157 & & $59.0(56.6)$ & [This work] models I \& II \\
\hline
\end{tabular}

(a) Composition was assessed, not measured

(b) Values from recommended model I are highlighted by bold font

original experimental work on the congruent melting of SiP phase, published by Ugai et al., ${ }^{[34]}$ who also measured the congruent melting point of $\mathrm{SiP}_{2}$ with samples in the actual composition range of the compounds, 50 to 75 at.\% P. This example emphasizes the importance of tracing back to original experimental publications to assess the reliability of these data. Also, one should not rely solely on "reviewed" data which might have been copied again and again until the actual source fades away. Thus, we used the melting temperature data from Ugai et al. ${ }^{[34]}$ for optimization. The calculated invariant reactions of the Si-P system are listed in Table 4 . For the $(\mathrm{Si})+\mathrm{SiP}$ eutectic temperature a very good agreement of our preferred model I with the experimental work is noted. For both congruent melting points the present calculation is much closer to the accepted experimental work $^{[34]}$ compared to the calculation by Jung and Zhang ${ }^{[5]}$ but still about $9 \mathrm{~K}$ lower than the experimental data. ${ }^{[34]}$ However, the gas pressure calculated at the congruent melting points is higher than the experimental values, ${ }^{[34]} 13$ bar (calc.) compared to 2.7 bar (exp.) for SiP and 60 bar (calc.) compared to 14.6 bar (exp.) for $\mathrm{SiP}_{2}$. This discrepancy is discussed in "Thermodynamic properties of SiP compounds" section.

For the eutectic $\mathrm{L}=\mathrm{SiP}+\mathrm{SiP}_{2}$ a temperature of $1125^{\circ} \mathrm{C}$ is reported by Ugai et al., ${ }^{[34]}$ which is much below the congruent melting temperatures in the same experimental study, ${ }^{[34]} 45 \mathrm{~K}$ lower for $\mathrm{SiP}$ and $53 \mathrm{~K}$ for $\mathrm{SiP}_{2}$, Table 4. These huge differences cannot be reconciled by any realistic thermodynamic description. For the difference between the congruent melting temperature of $\mathrm{SiP}$ and that eutectic our calculation gives only $4 \mathrm{~K}$ and that of ${ }^{[5]} 3 \mathrm{~K}$. These calculated values are in agreement with each other and less than $1 / 10$ of the reported experimental value, which should therefore be taken with care.

As described in "Phase equilibrium data" section, the experimental solubility data of $\mathrm{P}$ in ( $\mathrm{Si}$ ) phase are scattering

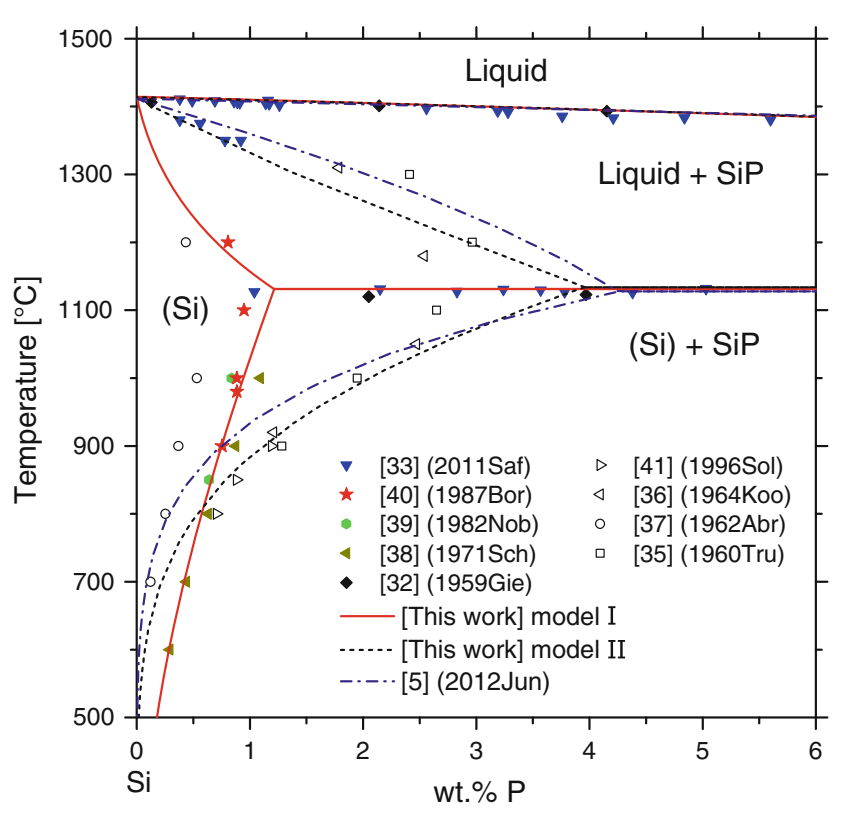

Fig. 3 Comparison of the calculated phase boundaries and experimental data at the Si-rich side of the Si-P phase diagram, highlighting the solubility of $\mathrm{P}$ in solid $(\mathrm{Si})$ phase

and contradict each other. We classified them into two groups and accordingly developed two sets of thermodynamic parameters for the diamond structure ( $\mathrm{Si}$ ) phase, labeled as model I and model II. Figure 3 presents the calculated phase diagram with the two alternative models together with all available experimental data. Also shown for comparison is the calculated phase diagram from ${ }^{[5]}$ which we produced by using the software Factsage and the published parameter values ${ }^{[5]}$ corrected from the typos as 
Table 5 Standard enthalpy of formation of the Si-P compounds, $\Delta_{\mathrm{f}} H^{\circ}$, reference states are diamond Si and white phosphorus $(\alpha-P)$ at $298.15 \mathrm{~K}$, together with the absolute entropy, $S_{298}^{0}$ at $298.15 \mathrm{~K}$

\begin{tabular}{|c|c|c|c|c|}
\hline Phases & $\Delta_{\mathrm{f}} H^{\circ} \mathrm{kJ} / \mathrm{mol}$-atoms & $S_{298}^{0} \mathrm{~J} / \mathrm{K} / \mathrm{mol}$-atoms & Method & Reference \\
\hline \multirow[t]{7}{*}{ SiP } & & 17.37 & Experimental & 23 (1979Uga) \\
\hline & -30.95 & 16.3 & Reviewed & 27 (1977Bar), 28 (1993Kub), 29 (2002Bin) \\
\hline & -39.52 & 6.3 & Derived & 25 (1938Bil) \\
\hline & -37.6 & 7.95 & Derived & 24 (1976Kor) \\
\hline & -31.61 & 14.70 & Calculated & 4 (2011Aru) \\
\hline & -31.65 & 17.37 & Calphad & 5 (2012Jun) \\
\hline & -31.65 & 17.37 & Calphad & [This work] \\
\hline \multirow[t]{2}{*}{$\mathrm{SiP}_{2}$} & -26.43 & 22.33 & Calphad & 5 (2012Jun) \\
\hline & -26.69 & 21.35 & Calphad & [This work] \\
\hline
\end{tabular}

"Calculated" values are from less stringent Calphad-type assessments

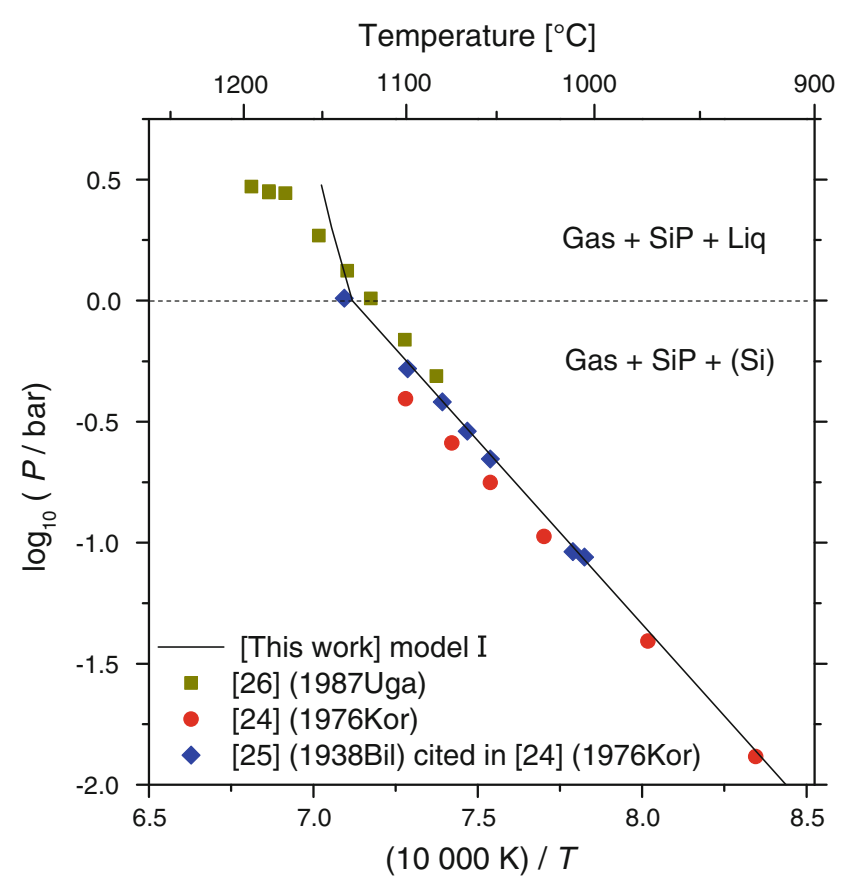

Fig. 4 Dissociation pressure of SiP. $\mathrm{P}$ is the total pressure, majority gas species are $\mathrm{P}_{2}$ and $\mathrm{P}_{4}$

detailed in the introduction. The solvus line calculated in this work with model I generally agrees with the experimental $[\mathrm{P}]_{(\mathrm{Si})}$ data from. ${ }^{[38-40]}$ For model II, the calculated solidus line agrees with experimental TG results, ${ }^{[33]}$ and the solvus line agrees with experimental results in. ${ }^{[35,36]}$ Model I presents lower solubility at eutectic temperature but higher solubility below $800{ }^{\circ} \mathrm{C}$ than model II.

Safarian and Tangstad ${ }^{[33]}$ gave a comprehensive and very detailed critical review of all the experimental $[\mathrm{P}]_{(\mathrm{Si})}$ data and recommend the solvus line that is in accord with our model I calculation, starting at the eutectic with $[\mathrm{P}]_{(\mathrm{Si})}=1.2 \mathrm{wt} . \% \mathrm{P}$ (model I) compared with their assessed value of 1.04 wt.\% P. We agree with their assessment on the solvus line. However, for the solidus line they present a hand-plotted curve from the $\mathrm{Si}$ melting point through their own data points down to

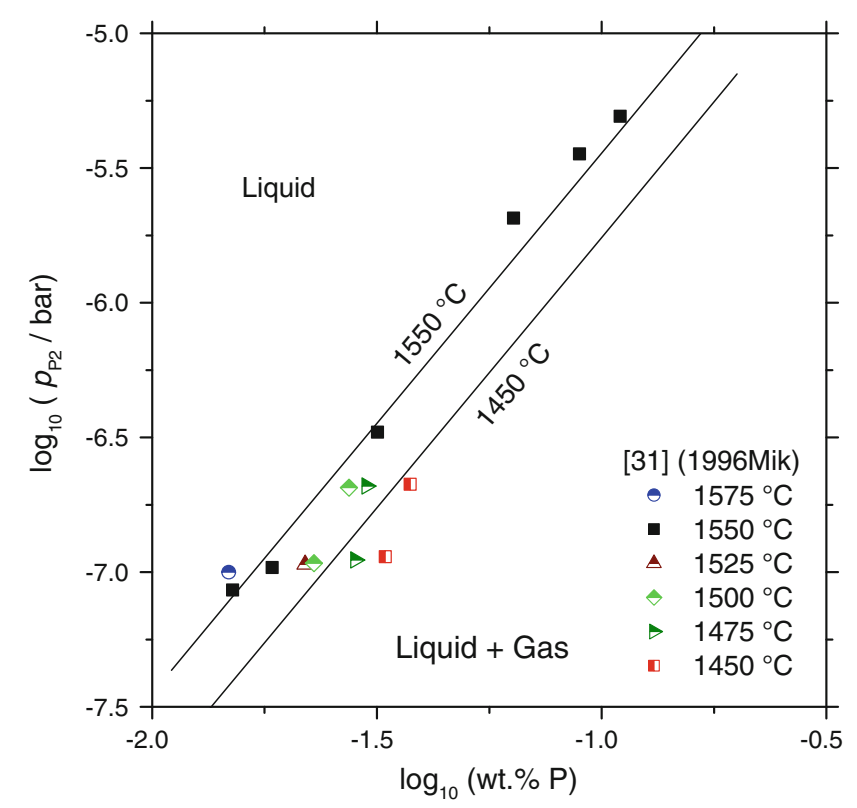

Fig. 5 Calculated solubility of $\mathrm{P}$ in molten $\mathrm{Si}$ as function of $\mathrm{P}_{2}$ (gas) partial pressure at 1550 and $1450{ }^{\circ} \mathrm{C}$ compared with the experimental data ${ }^{[31]}$

$1350{ }^{\circ} \mathrm{C}$ and continued with a strong retrograde solubility to meet the eutectic point at $[\mathrm{P}]_{(\mathrm{Si})}=1.04 \mathrm{wt} . \% \mathrm{P}^{[33]} \mathrm{We}$ have tried hard to reproduce that solidus line, but found it impossible to do that with any consistent thermodynamic calculation and sensible Gibbs energy functions of the ( $\mathrm{Si}$ ) and liquid phases. Retrograde solidus lines are known in other $\mathrm{Si}-\mathrm{X}$ systems, such as $\mathrm{Si}-\mathrm{Al}$, however, they generally occur with much smaller maximum solubility values, well below 1 at.\%. Since we found it impossible to reconcile the solidus data of ${ }^{[33]}$ with the solvus data of, ${ }^{[33]}$ the alternative model II was developed to demonstrate the impact if the solidus data of ${ }^{[33]}$ are accepted together with the group II solid solubility data with larger values of $[\mathrm{P}]_{(\mathrm{Si})}$ near the eutectic temperature. ${ }^{[35,36]}$ The consequence is an almost four times larger value of $[\mathrm{P}]_{(\mathrm{Si})}$ at the eutectic as compiled in Table 3. This model II is not recommended in the present 
work mainly because we agree with Safarian and Tangstad ${ }^{[33]}$ that the more recent solvus data of group I ${ }^{[38-40]}$ highlighted by solid symbols in Fig. 3, are more reliable. It is the beauty of the Calphad method to reveal the inconsistency with the solidus data and to demonstrate that we cannot have both, as attempted in the hand-plotted solidus of ${ }^{[33]}$ The reason for the discrepancy remains unsolved and might be found in the intricacy of the experimental methods. It is noted that the partial phase diagram calculated by Tang et al. ${ }^{[1]}$ gives a medium value of $[\mathrm{P}]_{(\mathrm{Si})}=2.5 \mathrm{wt} . \% \mathrm{P}$ at the eutectic, however, that is not a proper Calphad assessment since none of the thermodynamic, vapor pressure and other phase equilibrium data had been considered or shown in a comparison. In Fig. 6 of Ref 1 the labeling of the data points by "Tamura" is in error, these are probably the various data points by Trumbore ${ }^{[35]}$. Actually, from the original work by Tamura $^{[45]}$ only a single value for $[\mathrm{P}]_{(\mathrm{Si})}=1.1 \mathrm{wt} . \% \mathrm{P}$ at $1050{ }^{\circ} \mathrm{C}$ might be extracted, but it is unclear if that is an equilibrium value saturated with $\mathrm{SiP}$.

\subsection{Thermodynamic Properties of SiP Compounds}

Table 5 lists the calculated thermodynamic properties of $\mathrm{SiP}$ and $\mathrm{SiP}_{2}$ phase compared with previous calculation and experiment results. The absolute entropy value $S_{298}^{\mathrm{o}}$ of the $\mathrm{SiP}$ phase was determined to be $17.37 \mathrm{~J} / \mathrm{K} / \mathrm{mol}$-atoms by the experimentally measured low-temperature heat capacity data of Ugai et al. ${ }^{[23]}$. The enthalpy value $-31.65 \mathrm{~kJ} / \mathrm{mol}$-atoms was optimized based on the dissociation pressure of SiP phase experimental data. ${ }^{[24-26]}$ The good agreement of the calculated dissociation pressure of SiP phase with the experimental data, especially in the range below 1 bar, is shown in Fig. 4. The calculated solid lines reflect the temperature dependence of the three-phase equilibria $\mathrm{Gas}+\mathrm{SiP}+(\mathrm{Si})$ and $\mathrm{Gas}+$ $\mathrm{SiP}+$ Liquid, whereas the dotted line marks the pressure of the truly invariant four-phase equilibrium $\mathrm{Gas}+\mathrm{SiP}+(\mathrm{Si})+$ Liquid, $P=0.975$ bar. The corresponding temperature is the same as for the eutectic, liquid $=(\mathrm{Si})+\mathrm{SiP}, 1131{ }^{\circ} \mathrm{C}$, because the pressure dependence of the condensed phases is negligible and not modeled. For the SiP phase, we agree with the thermodynamic assessment of Jung and Zhang ${ }^{[5]}$, based on absolute entropy, heat capacity and subsequently determined enthalpy from vapor pressure data, without using the melting point data. Thus, the thermodynamic properties for solid SiP are the same, as given in Table 5. The different congruent melting point, given in Table 4, results from our different modeling of the liquid phase.

It was found impossible to reconcile in a consistent thermodynamic assessment the experimentally determined $d^{[34]}$ high congruent melting temperature of $\mathrm{SiP}$ $\left(1170{ }^{\circ} \mathrm{C}\right.$, Fig. 2$)$ with the low experimental pressure value at that point from the same group of authors ${ }^{[26]}$ (2.7 bar, Fig. 4); the calculated values are $1161{ }^{\circ} \mathrm{C}$ and 13 bar. The calculated three-phase equilibrium line $\mathrm{Gas}+\mathrm{SiP}+$ liquid starts from the very well established four-phase equilibrium at 0.975 bar and $1131{ }^{\circ} \mathrm{C}$; with increasing temperature the liquid composition along that line increases from the eutectic towards the SiP stoichiometry while the pressure must increase drastically. Beyond the congruent point, not

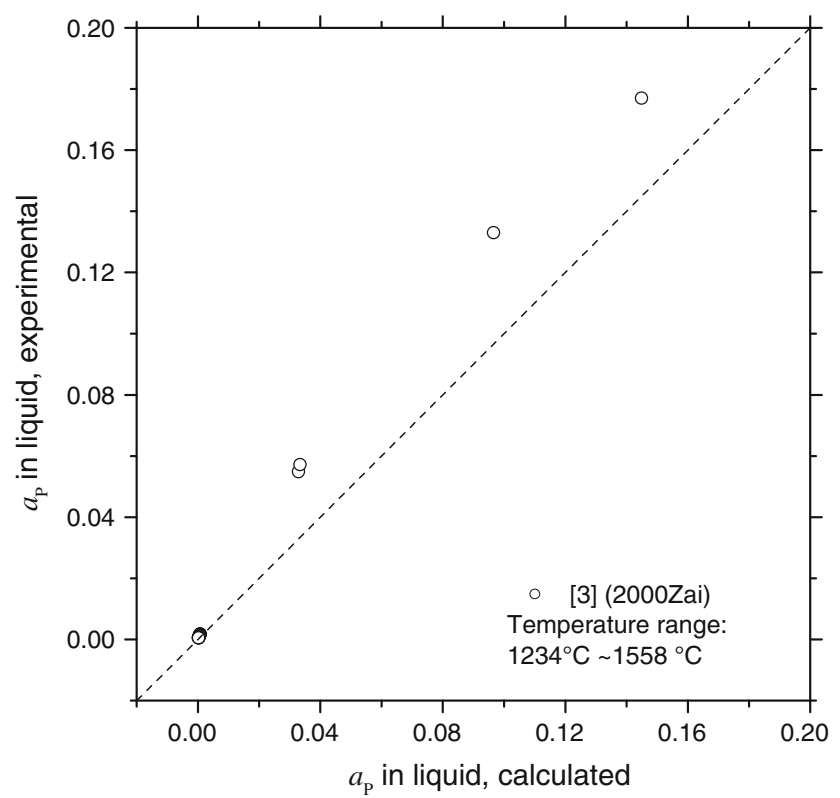

Fig. 6 Comparison of calculated with experimental $\mathrm{P}$ activity, ${ }^{[3]}$ $a_{\mathrm{P}}$, measured at random in the composition range $x_{\mathrm{P}}=0.001$ to 0.265 . Reference state of $a_{\mathrm{P}}$ is pure liquid P. The dashed line, indicating perfect agreement, is a guide for the eye only

shown in Fig. 2, the calculated line $\mathrm{Gas}+\mathrm{SiP}+$ liquid continues to higher pressure with decreasing temperature. If one now assumes a lower congruent melting temperature of $\mathrm{SiP}$, such as $1150{ }^{\circ} \mathrm{C}$ where the calculated line in Fig. 4 ends, all the solid $\mathrm{SiP}$ in the heating experiment will have been consumed and the liquid has attained 50 at.\% P, which remains constant on further heating. The corresponding calculated line of the two-phase equilibrium gas + liquid (50 at.\% P) will show a strong break and the pressure will increase only slightly with temperature. It is quite obvious from Fig. 4 that such a bended line should be in better agreement with the three data points of Ugai et al. ${ }^{[26]}$ in the range $1173-1195{ }^{\circ} \mathrm{C}$. Jung and Zhang ${ }^{[5]}$ assumed that kind of interpretation in their assessment (Fig. 2 in [5]). They chose $1137{ }^{\circ} \mathrm{C}$ as congruent melting temperature of SiP, but it is noted that the pressure-discrepancy increases in their $\mathrm{Gas}+\mathrm{SiP}+$ liquid range. ${ }^{[5]}$

The reason why we consider the experimental melting temperature data of $\mathrm{SiP}^{[34]}$ more reliable compared to the experimental pressure data ${ }^{[26]}$ is not only that the pressure measurement is probably more intricate. Inspection of Fig. 4 reveals that all of the six experimental pressure data from Ugai et al. ${ }^{[26]}$ in the range $1083-1173{ }^{\circ} \mathrm{C}(0.49-2.78$ bar $)$ are located on an exactly straight line. That is impossible from a thermodynamic point of view since at the four-phase equilibrium (at about 1 bar) a strong bend must occur as shown by the calculated line. Due to these reasons the reported pressure value of $14.6 \mathrm{bar}^{[26]}$ at the congruent melting point of $\mathrm{SiP}_{2}$ is also doubted. Finally, it is noted that in the present assessment of the liquid phase parameters none of the experimental data involving the liquid/gas equilibria were used. Since the Gibbs energies of the gas 
phase species are also determined independently, all of the calculated liquid/gas equilibria represent predictions. These predictions reasonably reproduce the experimental data in Fig. 5, as detailed later.

Evaluated from their measured SiP pressure data, Korb and Hein $^{[24]}$ also report their derived data for $\Delta_{\mathrm{f}} H^{\circ}=-37.6 \mathrm{~kJ} /$ mol-atoms and $S_{298}^{\circ}=7.95 \mathrm{~J} / \mathrm{K} / \mathrm{mol}$-atoms, and cited the derived values from Biltz, ${ }^{[25]} \Delta_{\mathrm{f}} H^{\circ}=-39.52 \mathrm{~kJ} / \mathrm{mol}$-atoms and $S_{298}^{\mathrm{o}}=6.3 \mathrm{~J} / \mathrm{K} / \mathrm{mol}$-atoms. It is obvious from Table 5 that these derived values differ greatly from the assessed values, the entropies are off by a factor larger than 2 . This is emphasized because some assessors only use the derived enthalpy data rather than the original pressure data (or partial pressure or activity data) for optimization. That must be avoided since true Calphad assessments use original data only. The full information contained in the vapor pressure data of Ref 24,25 is shown in Fig. 4 and already implemented in the present Calphad assessment by that direct comparison.

\subsection{Thermodynamic Properties of the Liquid Phase}

We agree with the statement by Jung and Zhang ${ }^{[5]}$ that the original experimental partial pressure data obtained by Miki et al. ${ }^{[31]}$ are certainly not less reliable than the activity data obtained by Zaitsev et al. ${ }^{[3]}$. During our optimization process, we also found that the activity data, $a_{\mathrm{P}}$, in Ref 3 are inconsistent with each other. At sample composition $x_{\mathrm{P}}=0.201$ with increasing temperature $\left(1299 \rightarrow 1345 \rightarrow 1384{ }^{\circ} \mathrm{C}\right)$ the $a_{\mathrm{P}}$ values go through a minimum $\left(a_{\mathrm{P}}=0.131 \rightarrow 0.119 \rightarrow\right.$ 0.133 ). In a single phase liquid region that is strange from a thermodynamic point of view, and our function $a_{\mathrm{P}}=\mathrm{f}(T)$ is monotonous as it rightly should be. Surprisingly, the claimed "calculated" results given in Table 1 of Ref 3 reflect the same trend with a minimum, but when we used their published parameters we cannot reproduce their calculated values using either Pandat or Thermo-calc software. The possibility of parameter-typo might be excluded because the same experimental activity data were also published in two other papers. ${ }^{[4,46]}$ The other problem with the two sets of thermodynamic descriptions of that group ${ }^{[3,4]}$ is that the claimed "calculated" phase diagrams contain the inconsistent $\mathrm{L}+\mathrm{G} /$ $\mathrm{G}$ phase boundary as described above in "Phase diagram" section. During our optimization process, we found it difficult to fit most of the activity data ${ }^{[3]}$ and to simultaneously agree with the well established $(\mathrm{Si})+\mathrm{SiP}$ eutectic temperature and a reasonable SiP Gibbs energy function. Thus we assigned lower weight for the activity data ${ }^{[3]}$ than to the partial pressure data. ${ }^{[31]}$ Figure 5 demonstrates that the relationship between the partial pressure of the majority species $\mathrm{P}_{2}(\mathrm{~g})$ and $\mathrm{P}$-content in Si-rich liquid experimentally obtained by Miki et al. ${ }^{[31]}$ are reasonably reproduced by the current calculation. Zaitsev et al. ${ }^{[3]}$ have reported their original experimental $a_{\mathrm{P}}$ values chosen at random in the composition range $x_{\mathrm{P}}=0.001-0.265$ and temperature interval $1234-1558^{\circ} \mathrm{C}$. The only way to compare their random data with the present thermodynamic calculation is shown in Fig. 6, where the calculated and experimental activity data are shown for selected $\left(x_{\mathrm{P}}, T\right)$ conditions. It is noted that the experimental $a_{\mathrm{P}}$ values $^{[3]}$ are always higher than the calculated values by about $20-40 \%$, but still in the same order of magnitude.

\section{Conclusion}

A Calphad assessment of the Si-P system was performed based on critical review of all available original experimental data. It is demonstrated that a simple disordered substitutional solution model is sufficient for the liquid phase. Assuming short-range ordering in the Si-P liquid phase may not be justified. The associate solution model with an assumption of even two associates in the liquid, $\mathrm{Si}_{2} \mathrm{P}$ and $\mathrm{SiP}$, with "large negative magnitudes" of the parameters $^{[3]}$ is certainly not justified. For the modified quasi-chemical model, also assuming short-range ordering in the liquid, we have to acknowledge that less parameters have been used with that model by Jung and Zhang ${ }^{[5]}$ compared to the present subregular solution model. On the other hand, the calculated temperature of the (Si)-SiP eutectic with the recommended model I is somewhat closer to the experimental data compared to. ${ }^{[5]}$ Also the isothermal phase boundary $\mathrm{L} / \mathrm{L}+\mathrm{P}_{2}$ (gas) calculated in the present work, Fig. 5, is closer to the experimental data ${ }^{[31]}$ compared to. ${ }^{[5]}$ A larger difference is to be pointed out for the congruent melting temperature of SiP, where the different experimental data of ${ }^{[33]}$ were accepted by Jung and Zhang, ${ }^{[5]}$ as shown in Table 4 . These melting point data of Safarian and Tangstad ${ }^{[33]}$ are rejected in the present study; the reasons are detailed in "Phase diagram" section. The only direct experimental value of $1170{ }^{\circ} \mathrm{C}$ by Ugai et al. ${ }^{[34]}$ is reflected better by the current modeling; the calculated congruent melting temperature is $24 \mathrm{~K}$ above that of. ${ }^{[5]}$ However, the gas pressure at the congruent melting point calculated in this work is higher than the experimental value $^{[34]}$ and better reflected by the modeling of. ${ }^{[5]}$

The most significant distinction of this work compared to the first complete and serious thermodynamic assessment of the Si-P system by Jung and Zhang ${ }^{[5]}$ is worked out in the description of the solid solubility of phosphorus in (Si). Alternative model descriptions (I and II) for the Gibbs energy of the $(\mathrm{Si})$ solid solution phase were developed to reveal the consequences in describing the largely scattering solubility data. Two alternative sets of consistently calculated phase boundaries of the ( $\mathrm{Si}$ ) phase are shown. It is impossible to reconcile the experimental solidus data (1414$1350{ }^{\circ} \mathrm{C}$ range) by Safarian and Tangstad ${ }^{[33]}$ with the experimental solvus data at the eutectic from the same work, ${ }^{[33]}$ Fig. 3. Accepting the experimental solidus data ${ }^{[33]}$ results in four times larger value of $[\mathrm{P}]_{(\mathrm{Si})}$ at the eutectic. The corresponding calculation using model II results in ( $\mathrm{Si})$ phase boundaries similar to those given by Jung and Zhang ${ }^{[5]}$. However, we recommend using the results of the present model I based on the probably more reliable lower values of $[\mathrm{P}]_{(\mathrm{Si})}$ along the solidus as detailed in "Phase diagram" section. The physical reason for the discrepancy between the solidus and solvus data, encompassed by models I and II, remains unsolved. 


\section{Acknowledgment}

This study is supported by the German Research Foundation (DFG) in the Bundled Proposal "PAK499" under Grant No. Schm 588/39.

\section{References}

1. K. Tang, E.J. Oevrelid, G. Tranell, and M. Tangstad, A Thermochemical Database for the Solar Cell Silicon Materials, Mater Trans., 2009, 50(8), p 1978-1984

2. K.M. Kim, I.S. Kwon, C.H. Lee, and E.P. Yoon, Effect of Phosphorus on Modification of Eutectic Silicon in Al7Si03Mg Alloy, Mater. Sci. Technol., 2000, 16(3), p 243-248

3. A. Zaitsev, N. Shelkova, and A. Kodentsov, Thermodynamic Properties and Phase Equilibria in the Silicon-Phosphorous System, J. Phase Equilib., 2000, 21(6), p 528-533

4. N. Arutyunyan, A. Zaitsev, and N. Shaposhnikov, Analysis of Thermodynamic Properties and Phase Equilibria in the Si-P System, Russ. J. Phys. Chem. A, 2011, 85(6), p 911-915

5. I.-H. Jung and Y. Zhang, Thermodynamic Calculations for the Dephosphorization of Silicon Using Molten Slag, JOM, 2012, 64(8), p 973-981

6. C.W. Bale, E. Bélisle, P. Chartrand, S.A. Decterov, G Eriksson, K. Hack, I.H. Jung, Y.B. Kang, J. Melançon, A.D. Pelton, C. Robelin, and S. Petersen, FactSage Thermochemical Software and Databases-Recent Developments, Calphad, 2009, 33(2), p 295-311

7. J.-O. Andersson, T. Helander, L. Höglund, P. Shi, and B. Sundman, Thermo-Calc \& Dictra, Computational Tools for Materials Science, Calphad, 2002, 26(2), p 273-312

8. W. Cao, S.L. Chen, F. Zhang, K. Wu, Y. Yang, Y.A. Chang, R. Schmid-Fetzer, and W.A. Oates, PANDAT software with PanEngine, PanOptimizer and PanPrecipitation for multicomponent phase diagram calculation and materials property simulation, Calphad, 2009, 33(2), p 328-342

9. P. Villars and L.D. Calvert, Pearson's Handbook of Crystallographic Data for Intermetallic Phases, ASM, Metals Park, 1985

10. D.E.C. Corbridge and E.J. Lowe, Structure of White Phosphorus: Single Crystal x-Ray Examination, Nature, 1952, 170(4328), p 629

11. H. Thurn, H. Krebs, Über Struktur und Eigenschaften der Halbmetalle. XXII. Die Kristallstruktur des Hittorfschen Phosphors, Acta Crystallogr., 1969, 25(1), p 125-135

12. C.G. Beck and R. Stickler, Crystallography of SiP and SiAs Single Crystals and of SiP Precipitates in Si, J. Appl. Phys., 1966, 37(13), p 4683-4687

13. T. Wadsten, Synthesis and Structural Data of SiP, Acta Chem. Scand., 1969, 23(7), p 2532-2533

14. T. Wadsten, Preparative and Crystal Structure Studies on Orthorhombic Silicon Monophosphide, Chem. Scr., 1975, 8, p 63-69

15. T. Wadsten, The Crystal Structures of $\mathrm{SiP}_{2}, \mathrm{SiAs}_{2}$, and GeP, Acta Chem. Scand., 1967, 21(2), p 593-594

16. A.J. Spring Thorpe, The Preparation of Single Crystal Orthorhombic $\mathrm{SiP}_{2}$, Mater. Res. Bull., 1969, 4(2), p 125-128

17. T. Wadsten, Synthesis of a Pyrite-Type Modification of $\mathrm{SiP}_{2}$, Acta Chem. Scand., 1967, 21(5), p 1374-1376

18. P.C. Donohue, W.J. Siemons, and J.L. Gillson, Preparation and Properties of Pyrite-Type $\mathrm{SiP}_{2}$ and $\mathrm{SiAs}_{2}, J$. Phys. Chem. Solids, 1968, 29(5), p 807-813

19. A.T. Dinsdale, SGTE Data for Pure Elements, Calphad, 1991, 15(4), p 317-425
20. S-M. Liang, R. Schmid-Fetzer, Thermodynamic Assessment of the Al-P System Based on Original Experimental Data, Calphad, accepted

21. G. Fritz and H.O. Berkenhoff, Über ein Siliciumphosphid $\mathrm{Si}_{2} \mathrm{P}$, Z. anorg. allg. Chem., 1959, 300(3-4), p 205-209

22. R. Olesinski, N. Kanani, and G. Abbaschian, The P-Si (Phosphorus-Silicon) System, J. Phase Equilib., 1985, 6(2), p 130-133

23. Y.A. Ugai, A.F. Demidenko, V.I. Koshchenko, V.E. Yachmenev, L.I. Sokolov, and E.G. Goncharov, Thermodynamic Properties of Silicon and Germanium Mono-Phosphides, Inorg. Mater., 1979, 15(5), p 578-581

24. J. Korb and K. Hein, Dampfdruckuntersuchungen im System Zn-Si-P (Vapor-Pressure Investigations in System Zn-Si-P), Z. Anorg. Allg. Chem., 1976, 425(3), p 281-288, In German

25. W. Biltz, Sitzungs-Berichte Preußische Akademie Wissenschaften, Phys.-Math. K1. X, 1938

26. Y.A. Ugai, G.V. Semenova, L.I. Sokolov, and E.G. Goncharov, Thermal Dissociation of Silicon Monophosphide, Russ. J. Inorg. Chem., 1987, 32(6), p 875-877

27. I. Barin, O. Knacke, and O. Kubaschewski, Thermochemical Properties of Inorganic Substances (Supplement), Spring, Düsseldorf, 1977, p 654

28. O. Kubaschewski, C.B. Alcock, and P.J. Spencer, Metallurgical Thermochemistry, 6th ed., Pergamon Press Ltd, Oxford, 1993, p 309

29. M. Binnewies and E. Milke, Thermochemical Data of Elements and Compounds, 2nd ed., Wiley-VCH Verlag $\mathrm{GmbH}$, Weinheim, 2002, p 786

30. F. Philipp and P. Schmidt, The Cationic Clathrate $\mathrm{Si}_{46-2 x} \mathrm{P}_{2 x} \mathrm{Te}_{x}$ Crystal Growth by Chemical Vapour Transport, J. Cryst. Growth, 2008, 310(24), p 5402-5408

31. T. Miki, K. Morita, and N. Sano, Thermodynamics of Phosphorus in Molten Silicon, Metall. Mater. Trans. B, 1996, 27(6), p 937-941

32. B. Giessen and R. Vogel, Über das System Silizium-Phosphor, Z. Metallkd., 1959, 50(5), p 274-277, In German

33. J. Safarian and M. Tangstad, Phase Diagram Study of the Si-P System in Si-Rich Region, J. Mater. Res., 2011, 26(12), p 1494-1503

34. Y.A. Ugai, L.I. Sokolov, E.G. Goncharov, and V.S. Makarov, P-T-x Composition Diagram and Thermodynamics of Phase Equilibrium in the Silicon-Phosphorus System, Russ. J. Inorg. Chem., 1987, 32(5), p 727-729

35. F.A. Trumbore, Solid Solubilities of Impurity Elements Germanium and Silicon, Bell Syst. Tech. J., 1960, 39(1), p 205-233

36. E. Kooi, Formation and Composition of Surface Layers and Solubility Limits of Phosphorus During Diffusion in Silicon, $J$. Electrochem. Soc., 1964, 111(12), p 1383-1387

37. N.K. Abrikosov, V.M. Glazov, and C.-Y. Liu, Individual and Joint Solubilities of Aluminium and Phosphorus in Germanium and Silicon, Russ. J. Inorg. Chem., 1962, 7(4), p 429-431

38. F.N. Schwettmann and D.L. Kendall, Carrier Profile Change for Phosphorus-Diffused Layers on Low-Temperature Heat Treatment, Appl. Phys. Lett., 1971, 19(7), p 218-220

39. D. Nobili, A. Armigliato, M. Finnetti, and S. Solmi, Precipitation as the Phenomenon Responsible for the Electrically Inactive Phosphorus in Silicon, J. Appl. Phys., 1982, 53(3), p 1484-1491

40. V.E. Borisenko and S.G. Yudin, Steady-State Solubility of Substitutional Impurities in Silicon, Phys. Stat. Solidi, 1987, 101(1), p 123-127

41. S. Solmi, A. Parisini, R. Angelucci, A. Armigliato, D. Nobili, and L. Moro, Dopant and Carrier Concentration in 
$\mathrm{Si}$ in Equilibrium with Monoclinic SiP Precipitates, Phys. Rev. B: Condens. Matter, 1996, 53(12), p 78367841

42. I.M. Mackintosh, The Diffusion of Phosphorus in Silicon, $J$. Electrochem. Soc., 1962, 109(5), p 392-401

43. T. Massalski, J.L. Murray, L. Bennett, and H. Baker, Binary Alloy Phase Diagrams, American Society for Metals, Metals Park, OH, 1986
44. M. Zumbusch, M. Heimbrecht, and W. Biltz, Beiträge zur systematischen Verwandtschaftslehre. 90: Germaniumphosphid, Z. Anorg. Allg. Chem., 1939, 242(3), p 237-248

45. M. Tamura, Dislocation Networks in Phosphorus-Implanted Silicon, Philos. Mag., 1977, 35(3), p 663-691

46. A.I. Zaitsev, A.D. Litvina, N.E. Shelkova, Thermodynamic Properties of Si-P, Melts High Temp. (Translation from “Teplofizika Vysokikh Temperatur”), 2001, 39(2), p 227-232 